\title{
Apuntes de análisis comparativo de la legislación chilena y peruana en materia de Responsabilidad Penal de las Personas Jurídicas
}

IVÁn MiLLÁN GutiéRReZ

Abogado por la Universidad de Chile. Magíster en Derecho Penal por la Universidad de Chile. Ex Jefe de la Fiscalía Especializada en Delitos de Corrupción de Santiago, Chile. Profesor de Derecho Penal en la Facultad de Ciencias Jurídicas y Sociales de la Universidad Central de Chile.

\begin{abstract}
Álvaro Castro Lora
Abogado por la Universidad de Piura. Máster en Banking and Financial Law (LL.M.) por la Queen Mary University of London. Especialización en Fintech por el Massachusetts Institute of Technology-MIT. Especialización en Finanzas y Derecho Empresarial por la Universidad ESAN.
\end{abstract}

SUMARIO:

I. Introducción.

II. Chile.

1. Contexto.

2. Modelo de imputación.

3. Sanciones.

4. Los modelos de prevención de delitos.

5. Aplicación de la ley.

III. Perú.

1. Contexto.

2. Modelo de imputación.

3. Sanciones.

4. Los modelos de prevención de delitos.

5. Proyecto de reglamento de la ley.

IV. Conclusiones.

* El artículo fue recibido con fecha 09-11-18. 


\section{RESUMEN:}

El régimen de responsabilidad penal de las personas jurídicas rompió el viejo paradigma latino "societas delinquere non potest". La responsabilidad de las personas jurídicas es hoy una realidad en los ordenamientos jurídicos chileno y peruano, reflejo de la voluntad política de implementar mejores prácticas en las relaciones entre Estado y privados, incentivando a que las empresas se autorregulen y controlen las actividades de sus empleados y representantes.

Palabras clave: Responsabilidad penal, modelos de prevención de delitos, Compliance penal, modelos de imputación, integridad corporativa.

\footnotetext{
ABSTRACT:

The regime of criminal responsibility of legal entities broke the old Latin maxim "societas delinquere non potest". The responsibility of legal entities is now a reality in the Chilean and Peruvian legal systems, reflecting the political will to implement better practices in the relationships between the State and private entities, encouraging companies to self-regulate and control the activities of their employees and representatives.

Keywords: Criminal liability, crime prevention models, Compliance, imputation models, corporate integrity.
}

\section{INTRODUCCIÓN}

Uno de los fenómenos más novedosos en el ámbito penal de nuestro entorno en el último tiempo, ha sido la aprobación de leyes que sancionan directamente a las personas jurídicas por delitos cometidos por personas naturales adscritas a ellas bajo distintas modalidades, abandonando un paradigma que parecía inexpugnable en los sistemas penales continentales hasta hace poco, expresado en el conocido apotegma del "societas delinquere non potest".

En estas normativas, y más allá de las distintas denominaciones que se ha dado a la responsabilidad en ellas establecida - penal o administrativa-, se destacan notorias semejanzas, fenómeno animado sin lugar a duda por la globalización y favorecido por la fluidez sin precedentes de las comunicaciones.

Ha sido esta la forma coincidente de responder a amenazas contemporáneas a las que se enfrentan en mayor o menor grado todos los países - como la corrupción, el blanqueo de capitales y el terrorismo- en las que el derecho punitivo, en sus distintas formas, ha adquirido un rol protagónico.

Desde esta perspectiva, resulta útil una mirada comparada a la forma en que nuestros países están desarrollando estas nuevas instituciones. Este trabajo expone las normativas de Chile y
Perú, buscando relevar sus semejanzas y diferencias, a fin de que sirvan de referencia recíproca: lo aprendido en los ya casi diez años de vigencia de la Ley de responsabilidad penal de las personas jurídicas en Chile; y las novedosas soluciones a los problemas allí detectados que se proponen en la reciente Ley de responsabilidad administrativa del Perú.

Pero este examen comparado quiere también dejar testimonio del fecundo trabajo de cooperación que gradualmente se está produciendo en nuestros países en esta materia, tras el propósito común de fortalecer la institucionalidad democrática, propósito al que se convoca ahora a las empresas, las que de esa forma suman valor al asegurar su propia sustentabilidad.

\section{CHILE}

\section{Contexto.}

El reconocimiento de la responsabilidad penal de las personas jurídicas en Chile vino de la mano, al igual que en el Perú, de la necesidad de atender el requerimiento impuesto por la Organización para la Cooperación y el Desarrollo Económicos - "OECD" por sus siglas en inglés-a los países que postulan a formar parte de dicha organización internacional.

El Mensaje con que a principios del año 2009 el Vicepresidente de la República remitió el respec- 
tivo proyecto de ley al Congreso Nacional fue explícito sobre el particular: "el ingreso a la OCDE solo se materializará una vez que Chile cumpla con las diversas normas impuestas por la OCDE, entre las cuales se encuentra la Convención para combatir el Cohecho a Funcionario Público Extranjero". En efecto, dicha Convención, suscrita por Chile ya en el año 1997, exige a los Estados parte adoptar "las medidas que sean necesarias, de conformidad con sus principios jurídicos, para establecer la responsabilidad de las personas morales por el cohecho de un servidor público extranjero" y que: "El cohecho de un servidor público extranjero deberá ser castigable mediante sanciones penales eficaces, proporcionales y disuasorias".

En su idea matriz, el proyecto se valía de la tautológica expresión "legal" para llamar a esta responsabilidad. No obstante, a poco andar se la sugirió denominar directamente "responsabilidad penal de las personas jurídicas", siguiendo de esta forma la opinión de la mayoría de los expertos que concurrieron a asesorar al parlamento en cuanto la responsabilidad era de naturaleza penal, por lo que correspondía emplear la terminología pertinente. Las principales fuentes del proyecto estuvieron en las tendencias del derecho norteamericano y europeo, particularmente el italiano.

La aprobación definitiva de este proyecto confirmó una vez más aquello de que el legislador puede borrar de un plumazo estanterías repletas de doctrina: la oposición a la imputación penal de las personas jurídicas, que venía siendo superada tímidamente en la doctrina y en alguna legislación, quedó enterrada definitivamente con la vigencia de la Ley 20393 a partir del 2 de diciembre de 2009.

\section{Modelo de imputación.}

La responsabilidad penal de las personas jurídicas en la Ley 20393 se estructura de forma particularmente compleja. Básicamente se requiere la concurrencia de los siguientes elementos: a) Comisión de ciertos delitos: originalmente estos eran el cohecho de funcionarios públicos nacionales -artículo 250 del Código Penal-y extranjeros —artículo 251 bis del Código Penal-, el lavado de activos — artículo 27 de la Ley 19913-y el financiamiento del terrorismo - artículo 8 de la Ley 18314-. La Ley 20931, del 5 de julio de 2016, incorporó el delito de receptación a este catálogo.

b) Que estos delitos se hayan cometido directa o indirectamente en interés o para provecho de la persona jurídica.

c) Que el delito haya sido cometido por los dueños, controladores, responsables, ejecutivos principales, representantes o quienes realicen actividades de administración y supervisión en la empresa, o por personas naturales que estén bajo la dirección o supervisión directa de alguno de los sujetos anteriores.

d) Que el delito haya sido cometido dentro del ámbito de funciones y atribuciones propias de estas personas.

e) Que la comisión sea consecuencia del incumplimiento por parte de la persona jurídica de los deberes de dirección y supervisión.

Puede colegirse de lo anterior que, propiamente tal, el reproche que se hace a la persona jurídica es el incumplimiento de los señalados deberes de dirección y supervisión sobre ciertas personas naturales que desarrollan funciones a su amparo. La comisión de los delitos concretos como consecuencia del referido incumplimiento se ubicaría extramuros del referido reproche, pudiendo identificárseles para estos efectos como una condición objetiva de la punibilidad.

Pese a que el texto legal asume posición al calificar de "autónoma"1 la responsabilidad

1. Artículo 5 de la Ley 20931, “Ley sobre responsabilidad penal de las personas jurídicas”. 
penal, lo cierto es que el análisis sistemático de la legislación permite más bien ver en ella un modelo atenuado de responsabilidad derivada $^{2}$ o mixta ${ }^{3}$. Por una parte, presenta rasgos de responsabilidad vicaria o derivada, desde que se exige la comisión del delito por parte de un individuo obviamente distinto de la persona jurídica en sí. Y, por otra, se trata de una responsabilidad autónoma de la persona jurídica por el incumplimiento de los deberes de dirección y supervisión, un defecto de organización que aumenta a niveles socialmente intolerables el riesgo de afectación de ciertos bienes jurídicos.

La atenuación del carácter derivado de la responsabilidad penal se asume explícitamente cuando se establece que esta subsiste aun si la responsabilidad penal individual se hubiere extinguido por la muerte del responsable o por la prescripción de la acción existente a su respecto, o si aquel hubiese sido declarado rebelde o caído en enajenación mental conforme la legislación procesal, o incluso si no ha sido posible establecer la participación de los responsables individuales.

\section{Sanciones.}

El régimen sancionatorio de la Ley 20393 considera las siguientes penas:

a) Disolución de la persona jurídica o cancelación de la personalidad jurídica.

b) Prohibición temporal o perpetua de celebrar actos y contratos con los organismos del Estado.

c) Pérdida parcial o total de beneficios fisca- les o prohibición absoluta de recibirlos hasta por 5 años.

d) Multa a beneficio fiscal, que pueden fluctuar entre 200 y 20,000 unidades tributarias mensuales ${ }^{4}$.

\section{e) Penas accesorias.}

La determinación específica de la pena se vincula a diversos factores. La disolución o cancelación de la personalidad jurídica se reserva para la reiteración o reincidencia en el lavado de activos, y para la reincidencia en la receptación. Las demás penas en sus tramos más altos se aplican solo para el lavado de activos, y en sus tramos más bajos para el cohecho, el financiamiento del terrorismo y la receptación sin reincidencia. Y dentro de los tramos respectivos, la pena concreta atenderá a: los montos de dinero involucrados; el tamaño y la naturaleza de la persona jurídica; su capacidad económica; el grado de sujeción y cumplimiento de la normativa legal y reglamentaria y de las reglas técnicas de obligatoria observancia en el ejercicio de su giro o actividad habitual; la extensión del mal causado por el delito; y la gravedad de las consecuencias sociales y económicas o, en su caso, los daños serios que pudiere causar a la comunidad la imposición de la pena, cuando se trate de empresas del Estado o de empresas que presten un servicio de utilidad pública.

\section{Los modelos de prevención de delitos.}

La responsabilidad penal de las personas jurídicas en la legislación chilena reposa, entre otros supuestos, en el incumplimiento de los deberes de supervisión y dirección. En este aspecto es

2. HERNÁNDEZ, Héctor. "La introducción de la responsabilidad penal de las personas jurídicas en Chile". En: Polít. Crim, Vol. 5, No 9, Art. 5. Santiago: 2010, pp. 207-236.

3. FERNÁNDEZ, Hernán. “Comentarios al modelo de responsabilidad penal de las personas jurídicas establecido por la ley N²0.393 en relación a los delitos de cohecho". En: Revista Jurídica del Ministerio Público, № 43. Santiago: 2010, pp. 79-96.

4. Entre US\$15,000.00 y US\$1,500,000.00, aproximadamente. 
donde se reconoce la plena vigencia de los modelos de prevención de delitos.

La Ley 20393 prescribe que "se considerará que los deberes de dirección y supervisión se han cumplido cuando, con anterioridad a la comisión del delito, la persona jurídica hubiere adoptado e implementado modelos de organización, administración y supervisión para prevenir delitos como el cometido".

Puede concluirse de lo expuesto que, si uno de los requisitos del tipo penal es el incumplimiento de los deberes de dirección y supervisión —una omisión-, la demostración de la atención de los señalados deberes a través del hecho positivo contrario propuesto por la Ley - la existencia de modelos prevención- vuelve atípica la conducta. Esto es, la comisión de delitos por parte de las personas señaladas en el artículo 3 de la Ley —dueños, controladores, etc.- en interés o provecho de la persona jurídica no es punible si la persona jurídica cuenta con un modelo de prevención vigente con anterioridad a la comisión del ilícito. Cabe agregar que esta conclusión alcanza solo a la persona jurídica y no a la persona natural que intervino de una forma penalmente responsable en su comisión, a cuyo respecto rigen las reglas generales.

Sin perjuicio de lo expuesto, la adopción de modelos de prevención de delitos no es la única forma de demostrar el cumplimiento de los deberes de dirección y supervisión. El artículo 4 de la Ley dispone que, para tales efectos, las personas jurídicas "podrán" adoptar un modelo de prevención, lo que deja abierta la posibilidad, bastante hipotética por cierto, de acreditar que se dirigió y supervisó al personal hacia la evitación de delitos por otras vías que no signifiquen modelos que agoten los requisitos mínimos que impone la ley, o que al menos no cumplan todos ellos.

Los modelos de prevención deben contar con las siguientes exigencias para volver atípica la conducta enjuiciada:

a) Debieron ser adoptados e implementados con anterioridad a la comisión del delito.

b) Deberán ser aplicados de forma efectiva y mantenerse actualizados de acuerdo al cambio de circunstancias de la respectiva entidad.

c) Deben contar con algunos requisitos mínimos:

i. Designación de un encargado de prevención, nombrado por la máxima autoridad de la persona jurídica, dotado de autonomía, recursos y medios materiales, y provisto de acceso directo a la Administración.

ii. Establecimiento de un sistema de prevención, que considere:

- La identificación de las actividades o procesos que exponen al riesgo de comisión de delitos

- Protocolos, reglas y procedimientos que permitan al personal prevenir los delitos.

- Procedimientos de administración y auditoría de los recursos financieros.

iii. Métodos de aplicación efectiva, supervisión que detecte y corrija sus fallas y actualización.

La regulación de los modelos de prevención en la Ley es más bien somera e, incluso ambigua, desde que cabe la posibilidad de valerse de sustitutos para demostrar el cumplimiento de los deberes de dirección y supervisión. La carencia de criterios más específicos respecto de los modelos no ha sido suplida como hubiese sido deseable por la administración, ya que, a diferencia de lo que ocurre en Perú, no hay deber de reglamentar la materia. El único documento oficial que desarrolla esta materia hasta ahora es la "Guía Práctica de Buenas Prácticas de Investigación en Responsabilidad Penal de las Personas Jurídicas", elaborado por la Unidad Anticorrupción del Ministerio Público, cuyo título advierte

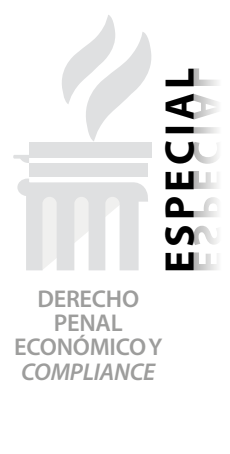


desde ya su carácter meramente orientador y su propósito de apoyar sobre todo la investigación que desarrollan los fiscales. Con todo, constituye un texto exhaustivo y útil que asigna algo de certeza frente al test más complejo que un modelo debería soportar: el de la investigación penal.

La Ley considera un sistema de certificación facultativa de los modelos de prevención a través de empresas de auditoría externa, sociedades clasificadoras de riesgo $u$ otras entidades registradas ante la Superintendencia de Valores y Seguros. La ley, sin embargo, no resuelve el rol que ha de asignarse a esta certificación, circunstancia que ha sido representada por el mecanismo de seguimiento de la Convención antisoborno de la $\mathrm{OCDE}^{5}$, que ha exhortado al país a clarificar los efectos legales de la certificación, y a generar estándares formales para las certificadoras relativos a: calificación, requerimientos de los certificados, metodología y conflictos de interés, exigencias que entendemos han sido atendidas de forma aún muy incipiente hasta ahora.

Lo expuesto no impide desconocer el importante rol que cumplen estas entidades. En lo estrictamente operacional proporcionan un escrutinio imparcial y especializado sobre la suficiencia y eficacia de los modelos. Y la vigencia restringida de los certificados, de un máximo de 2 años según disposición de la Superintendencia de
Valores y Seguros, asegura y colabora asimismo con la sostenibilidad del modelo en el tiempo.

Por nuestra parte, entendemos que la existencia de un modelo de prevención certificado de la forma dispuesta por la Ley, proporciona a la empresa un argumento crucial no solo para invocar la atipicidad de la conducta que se le imputa dada la existencia del modelo, sino que, aun en caso que la suficiencia y vigencia de este sea puesta en tela de juicio, permite demostrar la falta de conocimiento acerca de la ocurrencia de los supuestos fácticos de la infracción penal, esto es, la ausencia de dolo derivada de un error de tipo invencible.

\section{Aplicación de la ley.}

No existen estudios que den cuenta del grado de aplicación de la Ley en cuanto al número y/o porcentaje de empresas que en Chile han adoptado e implementado modelos de prevención de delitos.

Sí hemos podido verificar que, al menos todas las empresas listadas en el IPSA ${ }^{6}$ cuentan con modelos de prevención 7 . Por su parte, el número de empresas que han certificado sus modelos de prevención ha ido en aumento desde la fecha de vigencia de la Ley hasta el año 2016, decayendo levemente el año $2017^{8}$.

5. Phase 3 Report on Implementing The OECD Anti-Bribery Convention In Chile, March 2014, p. 20.

6. Índice de Precio Selectivo de las Acciones, que sigue el precio de las acciones de las 40 sociedades con mayor presencia bursátil en la Bolsa de Santiago.

7. Información extraída de la revisión efectuada por los autores a las páginas web de c/u estas empresas a la fecha de elaboración de este artículo.

8.

\begin{tabular}{c|c} 
Año & $\begin{array}{c}\text { Nempresas } \\
\text { certificadas }\end{array}$ \\
\hline 2011 & 5 \\
\hline 2012 & 92 \\
\hline 2013 & 284 \\
\hline 2014 & 392 \\
\hline 2015 & 462 \\
\hline 2016 & 533 \\
\hline 2017 & 498
\end{tabular}

Fuente: Elaboración propia de los autores sobre la base de información extraído del sitio web de la Comisión del Mercado Financiero. Disponible en: $<w w w$. cmfchile.cl>. 
Por su parte, los tribunales de justicia ya han tenido oportunidad de conocer casos relativos a responsabilidad penal de empresas. La mayoría de ellos ha culminado con suspensiones condicionales del procedimiento, fijándose condiciones de variada índole: iniciar trámites de disolución y liquidación de una sociedad, prestaciones económicas en beneficio de la comunidad de hasta el equivalente a US\$2,7 millones, pago de hasta US\$1,5 millones al erario público, otorgamiento de becas de estudio, implementación de modelos de prevención de delitos, etc.

Las sanciones aplicadas en procedimientos abreviados han consistido en multas de hasta el equivalente a US\$150,000.00, pérdida temporal de beneficios fiscales, prohibición temporal de celebrar contratos con el estado, y publicaciones de sentencias en periódicos de circulación nacional. Un caso ha sido absuelto en juicio oral al constatar el tribunal que "no puede haber una diferenciación entre la conducta desplegada por el único integrante de la organización de la empresa (...) y la acción de (su dueño)"'.

La totalidad de los casos mencionados provienen de delitos de cohecho de funcionarios públicos nacionales y en solo uno de ellos la empresa contaba con un modelo de prevención de delitos, el que fue considerado insuficiente por el ministerio público, al no contemplar control alguno sobre el centro de costos del gerente general que pagó las coimas, aunque el tema no fue finalmente objeto de controversia pues culminó con una suspensión condicional del procedimiento $^{10}$. No obstante, para los próximos meses se espera la discusión en juicio oral de un caso de cohecho imputado a una empresa que sí alega haber contado con un modelo de prevención eficiente, al menos durante parte del tiempo en que se cometieron los ilícitos, al que la fiscalía resta valor por falta de volun- tad de la alta administración en su implementación ${ }^{11}$.

\section{PERÚ}

\section{Contexto.}

El Perú ha ratificado los principales tratados internacionales en materia de lucha contra la corrupción, tales como la Convención de $\mathrm{Na}$ ciones Unidas contra la Corrupción, la Convención de Naciones Unidas contra la Delincuencia Organizada Transnacional y el Convenio Internacional para la represión de la Financiación del Terrorismo; los cuales exigen al Perú regular la responsabilidad autónoma de las personas jurídicas por su participación en los delitos de corrupción, lavado de activos y financiamiento del terrorismo, sea en el ámbito penal, civil o administrativo.

En ese sentido, el Perú asumió en el año 2000 el compromiso de cumplir las Recomendaciones № 3 y 5 del Grupo de Acción Financiera Internacional-GAFI y sus respectivas notas interpretativas, conforme a las cuales debía asegurarse que se aplique responsabilidad penal, civil o administrativa a las personas jurídicas involucradas en los delitos de lavado de activos y de financiamiento del terrorismo.

De esa manera, en abril de 2016 se aprobó la Ley 30424, estableciendo la responsabilidad administrativa de las personas jurídicas pero únicamente por el delito de cohecho activo transnacional previsto en el artículo 397-A del Código Penal.

En tanto resultaba necesario perfeccionar el marco normativo vigente y establecer un nuevo campo de responsabilidad administrativa que regule, además del delito de cohecho activo transnacional, la responsabilidad autóno-

9. Sentencia de 02-06-2015 del Tribunal Oral en lo Penal de Arica, causa RIT 33-2014

10. Causa RIT 10.969-2016 del $8^{\circ}$ Juzgado de Garantía de Santiago

11. Causa RIT Nº 8347 - 2014, del $4^{\circ}$ Juzgado de Garantía de Santiago 
ma de las personas jurídicas que participan en otros delitos de corrupción, tales como el delito de cohecho activo genérico - artículo 397 del Código Penal-y cohecho activo específico artículo 398 del Código Penal-, así como en los delitos de lavado de activos -artículos 1 al 4 del Decreto Legislativo 1106- y financiamiento del terrorismo - artículo 4-A del Decreto-Ley 25475 - , en enero de 2017 se aprobó el Decreto Legislativo 1352, el cual modificó diversos artículos de la Ley 30424.

Cabe recordar que cuando a fines de 2016 Marcelo Odebrecht reconoció haber pagado sobornos por US\$29 millones a funcionarios públicos peruanos entre los años 2005 y 2014, el gobierno del presidente Pedro Pablo Kuczynski se encontró desprovisto de instrumentos legales que le permitieran procesar penalmente a la compañía.

Si bien en el plano formal la Ley recurre al término "responsabilidad administrativa", la determinación de dicha responsabilidad no se llevará a cabo en sede administrativa, sino en sede penal, por un juez penal, en el marco y con las garantías de un proceso penal, aplicándose las disposiciones pertinentes del Código Penal y del Código Procesal Penal. En tal sentido, en palabras de Caro y Naval, algunos consideran que la Ley "recurre a una suerte de "fraude de etiqueta" al denominar "administrativa" a lo que en rigor es una responsabilidad penal corporativa"'2.

\section{Modelo de imputación.}

La responsabilidad penal de las personas jurídicas en la Ley 30424 se estructura de forma particularmente compleja. Básicamente se requiere la concurrencia de los siguientes elementos:

a) Comisión de ciertos delitos: originalmente este era el delito de cohecho activo transnacional. Posteriormente, con el Decreto
Legislativo 1352, el cual modificó diversos artículos de la Ley 30424, la responsabilidad autónoma de las personas jurídicas se extendió a delitos tales como el delito de cohecho activo genérico —artículo 397 del Código Penal-y cohecho activo específico —artículo 398 del Código Penal一, así como en los delitos de lavado de activos -artículos 1 al 4 del Decreto Legislativo 1106 - y financiamiento del terrorismo -artículo 4-A del Decreto-Ley 25475-. Finalmente, mediante Ley 30835 del 02 de agosto de 2018 se extendió a los delitos de colusión -artículo 384 del Código Penaly tráfico de influencias -artículo 400 del Código Penal-.

b) Que estos delitos hayan sido cometidos en su nombre o por cuenta de ellas y en beneficio, directo o indirecto de la persona jurídica.

c) Que estos delitos hayan sido cometidos por los socios, directores, administradores de hecho o derecho, representantes legales o apoderados de la entidad, o de sus filiales o subsidiarias, o por la persona natural que, estando sometida a la autoridad y control de las personas antes mencionadas, (i) haya cometido el delito bajo sus órdenes o autorización, o, (ii) porque las personas antes mencionadas han incumplido sus deberes de supervisión, vigilancia y control sobre la actividad encomendada, en atención a la situación concreta del caso.

El artículo 3 también señala que las personas jurídicas que tengan la calidad de matrices serán responsables si las personas naturales de sus filiales o subsidiarias han actuado bajo sus órdenes, autorización o con su consentimiento. Finalmente, establece que las entidades no son responsables cuando las personas naturales han cometido el delito "exclusivamente en

12. CARO CORIA, Dino Carlos y NAVAL LINARES, Virginia del Pilar. "Sobre el proyecto de Reglamento de la Ley 30424 de responsabilidad "administrativa» (penal) de las personas jurídicas". Disponible en: <https://legis.pe/sobre-proyecto-reglamento-ley-30424-responsabilidad-administrativa-penal-personas-juridicas/>. 
beneficio propio o a favor de un tercero distinto a la persona jurídica", regla complementaria a la prevista en el artículo 17.4 cuando la empresa cuenta con un programa de cumplimiento: "Se excluye también la responsabilidad de la persona jurídica, cuando cualquiera de las personas naturales señaladas en el artículo 3 comete el delito eludiendo de modo fraudulento el modelo de prevención debidamente implementado".

En el mundo existen dos modelos legislativos ideales de responsabilidad penal de personas jurídicas, por un lado un modelo de responsabilidad derivada, conforme al cual se hace recaer sobre la persona jurídica la responsabilidad penal de una persona natural en virtud de algún criterio de conexión entre una y otra, generalmente la circunstancia de ser la persona natural órgano o al menos subordinado del ente moral. Por otra parte, un modelo de responsabilidad autónoma u originaria, según el cual la responsabilidad surge directamente de una conexión entre el hecho prohibido y una característica de - o un cierto estado de cosas en - la entidad, siendo irrelevante la eventual responsabilidad de una persona natural.

La Ley peruana asume un modelo atenuado de responsabilidad derivada, predomina por una parte la necesidad de una conexión entre el individuo responsable y su hecho con la persona jurídica. Pero a la vez, el ente colectivo puede excluirse o atenuar su responsabilidad si ha instaurado un modelo de prevención de actos delictivos.

A esta interpretación se sigue oponiendo, sin embargo, el propio artículo 4 de la Ley, cuando indica que "La responsabilidad administrativa de la persona jurídica es autónoma de la responsabilidad penal de la persona natural", con lo que no es posible concluir que la sanción "administrativa" contra la persona jurídica es consecuencia inmediata del delito de la persona natural, y más porque luego el artículo 4 prescribe que "Las causas que extinguen la acción penal contra la persona natural no enervan la responsabilidad administrativa de las personas jurídicas". Y aún todavía porque el artículo 4, tras su reciente reforma, acota las causas de extinción de la ac- ción contra la persona jurídica a la prescripción y la cosa juzgada, eliminando la amnistía y el derecho de gracia previstos en la versión original de la Ley.

Estamos por lo tanto ante un régimen de responsabilidad autónoma de la persona jurídica, distinto y paralelo al de la persona física, y a la que algunos preferirían llamar solo "administrativa" o "civil patrimonial" para evitar el estigma que la pena acarrearía para la reputación de la empresa: no es lo mismo concluir que una corporación fue sancionada administrativamente por el delito de corrupción cometido por uno de sus empleados, a sentenciar que la empresa fue condenada penalmente por un acto de corrupción o lavado de activos cometido por ella.

\section{Sanciones.}

El régimen sancionatorio de la Ley 30424 considera las siguientes penas, las cuales pueden ser aplicadas de manera conjunta o individual, previo requerimiento del Ministerio Público o el juez penal:

a) Multa del doble al séxtuplo del beneficio obtenido o esperado. Según el artículo 7 de la Ley, cuando no se pueda determinar el valor del beneficio, el juez penal podrá determinar la multa entre 10 y 10.000 Unidades Impositivas Tributarias-UIT, atendiendo a los ingresos anuales de la persona jurídica al momento en que se cometió el delito.

b) La inhabilitación de la persona jurídica, en las modalidades de suspensión temporal —de 6 meses a 2 años - de las actividades sociales, la prohibición temporal — de 1 a 5 años- o definitiva de llevar a cabo actividades de la misma naturaleza en que se cometió, favoreció o encubrió el delito; y la inhabilitación definitiva para contratar con el Estado.

c) Cancelación de licencias, concesiones, derechos y otras autorizaciones administrativas y municipales.

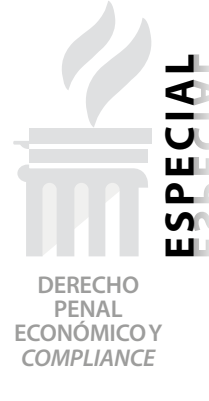

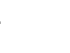


d) Clausura temporal — de 1 a 5 años - o definitiva de locales y establecimientos.

e) Disolución de la persona jurídica. Cabe señalar que la Ley excluye la aplicación de esta medida cuando se trate de personas jurídicas de derecho privado y empresas del Estado o sociedades de economía mixta que presten un servicio de utilidad pública, cuya interrupción pueda causar graves consecuencias sociales o económicas o daños serios a la comunidad.

Adicionalmente, la Quinta Disposición Complementaria Final de la Ley 30424 crea un Registro de Personas Jurídicas sancionadas administrativamente, de carácter público, a ser implementado por el Poder Judicial, donde se inscribirán temporal o definitivamente las sanciones administrativas impuestas, con expresa mención del nombre, la clase de sanción y duración, así como el detalle del órgano jurisdiccional y fecha de la sentencia firme, sin perjuicio de cursar parte a los Registros Públicos para su inscripción, en caso corresponda.

\section{Los modelos de prevención de delitos.}

La Ley establece como circunstancia eximente -artículo $17.1-$ y atenuante -artículo 12.d- de la responsabilidad administrativa, la implementación por parte de la persona jurídica de un Programa de Cumplimiento Normativo en materia Penal o de alguno de sus elementos - en adelante, "Modelo de Prevención"-, de manera previa o posterior al delito cometido, respectivamente. Según el artículo 17 de la Ley, los requisitos mínimos que deben contener los Modelos de prevención son los siguientes:

a) Un encargado de prevención -Oficial de Cumplimiento-, designado por el máximo órgano de administración de la persona jurídica y que ejerza sus funciones con autonomía.

b) La identificación, evaluación y mitigación de riesgos para prevenir la comisión de delitos a través de la persona jurídica. c) Implementación de procedimientos de denuncia.

d) Difusión y capacitación periódica del modelo de prevención.

e) Evaluación y monitoreo continuo del modelo de prevención.

Si la persona jurídica no puede acreditar el cumplimiento de estos elementos mínimos, sino de modo parcial, la Ley prevé la posibilidad de atenuar la sanción - artículo 12.e-. En ese examen debe tenerse en cuenta lo ya indicado, el artículo 17.2.5 no impone un modelo de prevención cerrado o acabado sino la opción de adecuarlo o construirlo a la medida, de acuerdo al grado de desarrollo de la organización. Se indica que este debe atender a las características de la persona jurídica, y en el caso de una micro, pequeña o mediana empresa, el modelo puede ser acotado según su propia naturaleza y características, pudiendo exigirse solo alguno de los elementos mínimos descritos. En cualquier caso, el punto de partida esencial e irrenunciable es la identificación, evaluación y mitigación de riesgos para prevenir la comisión de delitos, dado que sin ello no puede hablarse de Compliance en ningún sentido.

Conforme al artículo 17.2.5 de la Ley, señala que el contenido del modelo de prevención debe atender a "las características de la persona jurídi$c a$ ", de modo que en el caso "de la micro, pequeña y mediana empresa, el modelo de prevención será acotado a su naturaleza y características y solo debe contar con alguno de los elementos mínimos antes señalados". Y es que ello es indicativo de dos cosas en cuanto a la culpabilidad, primeramente que aun tratándose de empresas con una menor complejidad organizativa, es posible argumentar la falta de culpabilidad en base a un modelo de prevención igualmente menos complejo que, en cualquier caso, al igual que para la invocación de las eximentes incompletas, deberá contar necesariamente con el presupuesto esencial previsto en el artículo 17.2.2 de la Ley reformada, es decir la "identificación, evaluación y mitigación de riesgos para prevenir la comisión de los delitos previstos 
en el artículo 1 a través de la persona jurídica". Lo segundo, si el escaso grado de complejidad interna de la empresa impide diferenciar con nitidez a la persona jurídica de sus integrantes, entonces la empresa no podrá ser sancionada - y menos con una pena- porque carece de culpabilidad.

Un aspecto especialmente discutido desde los proyectos previos a la Ley 30424 es la certificación del modelo de prevención. El artículo 19 del texto original de la Ley, ahora derogado por el Decreto Legislativo 1352, preveía que el modelo de prevención podía certificarse por terceros debidamente registrados, el proyecto de Reglamento de julio de 2016 señaló en el artículo 15.1 como organismo acreditador a la Dirección de Acreditación del Instituto Nacional de Calidad-INACAL.

El texto reformado de la Ley 30424 ya no incluye indicaciones sobre la acreditación, pero el artículo 18 señala que la Superintendencia de Mercado de Valores-SMV deberá emitir un informe técnico, con valor pericial y como requisito de procedibilidad $-8^{\text {a }}$ Disposición Complementaria Final-, que analice la "implementación y funcionamiento del modelo de prevención". Sin dicho informe, el Fiscal no puede formalizar la investigación preparatoria contra la persona jurídica. Pero, ¿Cuánto conoce la SMV de corrupción, lavado de activos y financiación del terrorismo?, ¿Cuánto conoce la SMV sobre programas de cumplimiento relativos a tales delitos?, ¿Es función de la SMV conocer de estos asuntos?, ¿Debe la SMV pronunciarse sobre empresas que no supervisa porque no cotizan valores en el mercado bursátil o no las regula?

A estas cuestiones cabe sumar que este requisito de procedibilidad no es acorde con la competencia exclusiva y excluyente del Ministerio Público para perseguir el delito, de modo que el texto reformado de la Ley 30424 parece incorporar un gran candado cuya llave queda en manos de la SMV, es decir, bajo custodia del Poder Ejecutivo. Antecedentes negativos de esa mecánica tenemos, como son los casos de la persecución de los delitos tributario y aduaneros, o los delitos de abuso de poder económico en los años 90 y 2000, solo previa denuncia de la SUNAT o del INDECOPI, reglas derogadas con el Código Procesal Penal de 2004, precisamente porque invadían las competencias de la Fiscalía y ante la inconveniencia de dejar en un órgano administrativo la secuela del proceso penal mediante un tal requisito de procedibilidad. Sería por ello conveniente que el Congreso, en el proceso de revisión de la legislación delegada, derogue esta regla y señale, de ser el caso, al órgano público a cargo de acreditar los programas de cumplimiento a fin de hacer predecibles las condiciones para aplicar la eximente del artículo 17 de la Ley y, con ello, se impulse la expansión de una cultura empresarial de cumplimiento.

\section{Proyecto de reglamento de la Ley.}

Mediante Resolución Ministerial № 00061-2018JUS del 27 de febrero de 2018, el Ministerio de Justicia y Derechos Humanos dispuso la publicación del Proyecto de "Reglamento de la Ley 30424, Ley que regula la responsabilidad administrativa de las personas jurídicas por el delito de cohecho activo transnacional" -en adelante, el "Proyecto" - , el mismo que fue elaborado por el Ministerio de Justicia y Derechos Humanos y el Ministerio de Economía y Finanzas.

El Proyecto tiene como objeto establecer y desarrollar los estándares y requisitos mínimos de los modelos de prevención que las personas jurídicas pueden implementar en su organización con el fin de prevenir, identificar y mitigar los riesgos de comisión de delitos.

Así, se destaca el nivel de profundidad que alcanza el Proyecto en la regulación de los contenidos con que deben contar los modelos de prevención de delitos de la Ley 30424. Emprendimientos de este tipo no han sido abordados por otras legislaciones, dejando abiertos espacios de incertidumbre que solo habrán de ser cubiertos por una jurisprudencia que, por distintos motivos, no ha sido particularmente prolífica en estas materias en ninguno de los países que cuentan con legislaciones de este tipo.

Dicho esto, las propias referencias contenidas

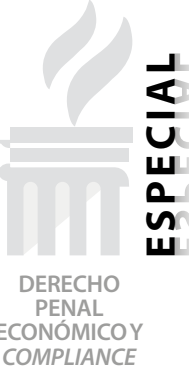


al final del Proyecto confirman que el texto sigue los procedimientos universalmente aceptados para una gestión planificada y metódica de riesgos de toda clase en las organizaciones. No obstante, el documento no alcanza el objetivo de hacerse cargo de los riesgos específicamente previstos por la Ley 30424, esto es, de la comisión de los delitos de cohecho, lavado de activos y financiamiento del terrorismo. Se trata de riesgos de alcances bastante precisos, gobernados por el sentido técnico que la doctrina penal y la jurisprudencia asignan a dichos tipos penales y por la casuística con que estas figuras se presentan en la realidad.

Esto se refleja, por ejemplo, en la clase de riesgos que pide gestionar que, tratándose de la comisión de delitos, se encuentran claramente delimitados por las instituciones del proceso penal, especialmente en lo relativo al principio de legalidad en la interpretación de los tipos penales y de las penas. Algo análogo ocurre con la evaluación del impacto que estas contingencias pueden acarrear para las empresas.

Merece destacarse, también, que el Proyecto no abunda en la proposición de medidas de control que mitiguen la exposición al riesgo específico de comisión de los delitos de la Ley 30424, limitándose a exigir medidas generales de control financiero y no financiero de los recursos de las empresas, muchas de las cuales no apoyan sino remotamente el control de estos riesgos.

Precisiones de esta naturaleza no solo ayudarían a las empresas a mantener modelos más robustos en su orientación de prevención de los delitos de cohecho, lavado de activos y financiamiento del terrorismo, sino que dotarían al organismo público que informará pericialmente estos modelos, de información de más calidad para ponderar su suficiencia de cara a la prevención de los delitos.

\section{CONCLUSIONES}

El examen comparado de las legislaciones peruana y chilena sobre la responsabilidad de las personas jurídicas por la comisión de delitos, permite detectar numerosas similitudes, las que se explican al tenor del entorno común del que provienen, en el que se destacan los compromisos internacionales asumidos por nuestros países, sobre todo aquellos ligados a la lucha contra la corrupción.

La conducta castigada se construye en ambos casos conforme modelos atenuados de responsabilidad derivada, coincidiendo en general los delitos base - con la salvedad de la receptación en Chile-; las personas naturales que han de cometer los ilícitos y su ligazón con la persona jurídica - con la adición del personal de las filiales y subsidiarias en el Perú-; la exigencia de un interés o provecho para la persona jurídica imputada; el incumplimiento de los deberes de supervisión, vigilancia y control como principal componente de reproche; las sanciones; la autonomía de la responsabilidad, etc. Y no obsta a lo anterior el que la legislación peruana llame responsabilidad "administrativa", y no penal como lo hace Chile, a aquella contenida en la Ley 30424, pues no parecen derivarse de ello divergencias perceptibles, salvo la ausencia del rótulo estigmatizador propio de la sanción penal.

La responsabilidad de las empresas por la comisión de delitos abre entonces un amplio campo de análisis en ambos países, imposible aún de dimensionar, en cuanto a la sintonía de las tradicionales categorías del derecho penal con las características de las empresas como sujetos de imputación, especialmente en los componentes subjetivos del delito. Quizás ello explique que, como ocurre en Chile y otros países con legislaciones más consolidadas, y como es dable esperar ocurra en el Perú, los casos penales relativos a empresas se zanjen en el marco de soluciones de justicia negociada, con componentes más bien preventivo especiales.

Debe destacarse el rol central que ambas legislaciones asignan a los modelos de prevención, a los que se reconoce virtud eximente o atenuante de la punición, o bien aparecen como condición necesaria de cualquiera suspensión del enjuiciamiento. Dada su relevancia, los modelos de prevención han dado pro- 
tagonismo a una nueva disciplina del derecho y el management: el Compliance, que ayuda a formalizar culturas corporativas ajustadas al derecho y pone de cargo de las personas privadas una tarea tradicionalmente reservada al Estado: la prevención de los delitos. Sin lugar a dudas, la reglamentación vía administrativa acometida por el Perú sobre los contenidos de los modelos de prevención constituye un gran avance, a fin de dotar de mayor certeza a este componente central de la configuración de la responsabilidad.

$\mathrm{Y}$, por lo mismo, no es casualidad que sea en este ámbito de los modelos de prevención donde se adviertan las principales tensiones normativas pendientes en la materia, particularmente en la validación que a su respecto se espera de organismos ajenos a la administración de justicia. En Chile, ello se advierte en el rol que ha de asignarse a la certificación de los modelos de prevención por entidades privadas y, en el caso del Perú, en el requerimiento de un informe técnico de la SMV como requisito de procedibilidad. En todo caso, el diseño profesional de los modelos y el compromiso de la administración corporativa en su implantación y continuidad resaltan como los ingredientes clave en la evitación de las contingencias legales que puedan derivarse de la comisión de delitos. 